\title{
Os aportes sócio-políticos da educação nutricional na perspectiva de um envelhecimento saudável ${ }^{1}$
}

\author{
The sociopolitical dimensions of nutrition \\ education from a healthy aging perspective
}

Maria do Socorro Silva ALENCAR 2,4

Francisco de Oliveira BARROS JÚNIOR ${ }^{3}$

Cecília Maria Resende Gonçalves de CARVALHO ${ }^{2,4}$

RE S U M O

\section{Objetivo}

O artigo analisa a contribuição da educação nutricional a partir das suas dimensões sócio-políticas que permeiam a promoção da saúde.

\section{Métodos}

Trata-se de uma oficina ludopedagógica sobre Nutrição, Saúde e Envelhecimento com idosos que freqüentaram um programa universitário da terceira idade, em encontros semanais. O estudo foi do tipo exploratório e descritivo, inserido na modalidade qualitativa, ancorada na observação participante e na entrevista semi-estruturada, tendo em vista a apreensão das concepções, atitudes e reflexões dos sujeitos em relação às práticas alimentares e ao estilo de vida, bem como ao próprio processo de envelhecimento.

\section{Resultados}

Os depoimentos dos idosos revelaram, como aspectos motivacionais para ingressar no programa e cursar a oficina, o ensino-aprendizagem, a integração social e o cuidado com a saúde. As concepções sobre a contribuição da educação nutricional para a promoção da saúde foram categorizadas nas temáticas: capacidade funcional e autocuidado.

\footnotetext{
1 Artigo elaborado a partir da dissertação de M.S.S. ALENCAR, intitulada "A Educação nutricional aportando dimensões sócio-políticas para um envelhecer bem-sucedido: vivências do programa terceira idade em Ação/UFPI". Universidade Federal do Piauí; 2006.

2 Universidade Federal do Piauí, Centro de Ciências da Saúde, Departamento de Nutrição. Campus Ministro Petrônio Portella, s/n., Ininga, 64049-550, Teresina, PI, Brasil. Correspondência para/Correspondence to: M.S.S. ALENCAR. E-mails: <maryhelpsa@terra.com.br>; <jalurisa@bol.com.br>.

${ }^{3}$ Universidade Federal do Piauí, Centro de Ciências Humanas e Letras, Departamento de Ciências Sociais. Teresina, PI, Brasil.

${ }^{4}$ Universidade Federal do Piauí, Núcleo de Pesquisa e Extensão Universitária para a Terceira Idade. Teresina, PI, Brasil.
} 


\section{Conclusão}

Frente aos resultados elaborou-se uma reflexão sobre a educação gerontológica, com ênfase nas dimensões sócio-políticas da educação nutricional, capaz de permear hábitos alimentares e estilo de vida saudáveis no curso da vida, pressupondo que ações interdisciplinares que visam à preservação, à manutenção ou à promoção da capacidade funcional do cidadão idoso, são possibilidades na direção da busca da qualidade de vida daqueles que envelhecem.

Termos de indexação: Educação alimentar e nutricional. Saúde do Idoso. Políticas públicas de saúde.

\section{A B S T R A C T}

\section{Objective}

This article analyzes the socio-political contribution of nutrition education in promoting health.

\section{Methods}

This is a ludo-educational workshop on nutrition, health and aging with elderly who attend a weekly university course for seniors. The study was of the exploratory and descriptive type, inserted in the qualitative modality, based on participant observation and semi-structured interview. The objective was to grasp the concepts, attitudes and reflections of the subjects regarding eating practices, lifestyle and aging process.

\section{Results}

The elderly stated that what motivated them to participate in the program and attend the workshop was the opportunity to learn, socialize and look after their health. Their concepts on how nutrition education contributes to promote health were categorized in the following themes: functional capacity and self-care.

\section{Conclusion}

The results lead us to reflect on education for the elderly, emphasizing the socio-political dimensions of nutrition education as it affects eating habits and lifestyle throughout life. The interdisciplinary actions that aim to preserve, maintain or promote functional capacity of the elderly are likely to improve the quality of life of the aging population.

Indexing terms: Food and nutrition education. Health of the elderly. Health public policy.

\section{N T R O D U ÇÃ O}

O Instituto Brasileiro de Geografia e Estatística (IBGE) estima que a população idosa no Brasil cresça cerca de 16 vezes, contra cinco vezes o crescimento da população em geral, até o ano de 2025. Esta evidência levará o Brasil a ocupar a sexta posição no ranking dos países mais populosos em número de pessoas idosas. Em termos absolutos, serão 32 milhões de indivíduos idosos ${ }^{1}$.

A acentuada mudança decorrente deste avanço demográfico faz com que o fenômeno do envelhecimento populacional se constitua em uma questão multifacetada na sociedade contemporânea demandando, assim, enfrentamentos interdisciplinares. Entre as questões de maior relevância estão aquelas do âmbito da Previdência
Social e da Saúde, pelo significativo impacto nas políticas econômicas e de assistência social do País, as quais precisam anexar a todo o processo de promoção ações integradas para a melhoria dos aspectos ligados à moradia, à saúde, à nutrição, à educação e à igualdade de oportunidades ${ }^{2}$.

Na área da saúde, estudos sinalizam que as características ambientais, a dieta, os hábitos de vida, os fatores de risco como, por exemplo, o fumo, o álcool, a obesidade, o colesterol, dentre outros, têm repercussão sobre os aspectos fisiológicos e metabólicos do organismo envelhecido. Tomando como espelho essa inferência, é possível buscar o envelhecimento saudável por meio da promoção da saúde e da prevenção das doenças, mantendo a capacidade funcional pelo maior tempo possível. Em sendo assim, é importante 
entender que a capacidade funcional no idoso é resultante do cuidado preventivo, a partir de um enfoque holístico da saúde, envolvendo alimentação, atividade física, atividade mental e equilíbrio emocional, incorporados no curso de sua vida.

Para tanto, a Política Nacional de Saúde do Idoso apresenta como norte a promoção do envelhecimento saudável, de modo a lhe garantir permanência no meio em que vivem exercendo, de forma independente, suas funções na sociedade $^{3}$.

Nesse sentido, as investigações vêm mostrando formas de melhorar a qualidade de vida daqueles que estão em processo de envelhecer e uma das alternativas tem sido o desenvolvimento de programas de saúde, os quais, segundo a Organização Mundial de Saúde (OMS), apresentam como base a comunidade, incluindo nesta proposta ações capazes de promover a saúde da pessoa idosa a partir da nutrição como estratégia prioritária4.

É, portanto, nesse enfoque que a educação nutricional se destaca entre os distintos estudos epidemiológicos, nos quais os resultados mostraram uma conexão entre comportamento alimentar e as alterações do processo saúde-doença.

Essa visão encontra respaldo nas diretrizes da OMS, que definiu, na década de 1980, a promoção da saúde "[...] como o processo que consiste em proporcionar aos povos os meios necessários para melhorar sua saúde e exercer um maior controle sobre a mesma" ${ }^{5}$, e, na Política Nacional de Alimentação e Nutrição (PNAN) ${ }^{6}$, cujo princípio norteador de ações educativas ressalta a socialização do conhecimento sobre alimentos e o processo de alimentação, da infância até a velhice, com vistas à adoção de estilos de vida saudáveis.

É importante salientar que a educação alimentar e nutricional, enquanto disciplina, tem como referência os princípios da educação em saúde que sejam capazes de permear a garantia do direito humano à alimentação como condição indispensável à vida e à construção da cidadania ${ }^{7}$.
Com base nesse conjunto de idéias, reconhece-se que a educação nutricional fundamentase como uma ação da nutrição aplicada, que orienta seus recursos em direção à aprendizagem, à adequação e à aceitação de hábitos alimentares saudáveis durante todo o ciclo de vida ${ }^{8}$. Este conceito está diretamente articulado com os conhecimentos científicos em Nutrição, tendo como proposição maior contribuir para a saúde individual e coletiva.

Nessa perspectiva este artigo tem como objetivo refletir sobre as vivências de sala de aula com idosos de uma universidade da terceira idade, a partir de uma oficina ludopedagógica sobre Nutrição, Saúde e Envelhecimento ressaltando, nesse processo, as dimensões sócio-políticas da educação nutricional que convergem para um modo de vida saudável.

\section{MÉTODOS}

A construção deste trabalho advém da Dissertação de Mestrado "A Educação nutricional aportando dimensões sócio-políticas para um envelhecer bem-sucedido: vivências do programa terceira idade em ação/UFPI, defendida em abril de 2006, no Programa de Pós-Graduação em Políticas Públicas, da Universidade Federal do Piauí (UFPI)".

Intentou-se, neste estudo, analisar o significado da contribuição da educação nutricional a partir das suas dimensões sócio-políticas. Nesse sentido, optou-se por realizar um estudo do tipo exploratório e descritivo, inserido na modalidade dialética, por se caracterizar como um dos métodos da pesquisa qualitativa direcionado à interpretação dos significados que os fenômenos têm para as pessoas que os vivenciam?

Em sendo assim, a investigação de natureza qualitativa mediada pelo estudo do tipo exploratório e descritivo encontra esteio no pensamento de Gill10, quando ele afirma que este possibilita ao investigador aumentar sua experiência em torno de determinada questão, assumindo o 
caráter descritivo quando observa, registra, analisa e correlaciona fatos com fenômenos sem os manipular.

Nessa direção, a dialética foi o suporte para aprofundar os significados atribuídos pelos sujeitos do estudo à contribuição da educação nutricional como estratégia sócio-política para a promoção da saúde dos idosos, ou seja, quais os sentidos que emergiram dos seus posicionamentos no tocante às concepções, às atitudes e às reflexões em relação às suas práticas alimentares e ao estilo de vida, bem como ao próprio processo de enveIhecimento, a partir do seu ingresso no Programa Terceira Idade em Ação (PTIA) e na oficina Nutrição Saúde e Envelhecimento.

Para tanto, as estratégias de campo empregadas foram a experiência didático-pedagógica na oficina "Nutrição, Saúde e Envelhecimento", do Programa Terceira Idade em Ação, complementada pelas técnicas de observação participante e entrevista semi-estruturada.

Segundo Minayo, o campo de pesquisa constitui-se como um recorte que o pesquisador faz em termos de espaço, representando uma realidade empírica a ser estudada a partir das concepções teóricas que fundamentam o objeto da investigação"11.

Nesse contexto, a oficina foi instituída no fluxograma do PTIA para a realização do trabalho de campo desta pesquisa, tendo como objetivos: discutir as inter-relações entre nutrição, saúde e envelhecimento na esfera da promoção da saúde; analisar a política de nutrição e saúde, em especial as ações de alimentação e nutrição como elementos centrais para a saúde da pessoa idosa e que sejam capazes de contribuir com a prevenção de agravos e a promoção de práticas alimentares adequadas às velhices.

Quanto aos aspectos metodológicos, foram adotados os princípios da Educação Crítica, com ênfase na concepção pedagógica problematizadora de Paulo Freire no que tange aos aspectos de conscientização, libertação, transformação dos sujeitos e humanização ${ }^{12}$, para refletir sobre a educação em saúde voltada para as práticas alimentares no contexto da promoção da saúde ${ }^{13}$.

No âmbito da Gerontologia, além dos posicionamentos pré-referidos, espelhou-se no conceito de Aranceta-Bartrina ${ }^{8}$, quando ela afirma que a Educação Nutricional constitui-se em uma ação que orienta seus recursos em direção à aprendizagem, à adequação e à aceitação de hábitos alimentares saudáveis.

Nesse caminho, foram buscadas nos fundamentos da educação, alternativas para readaptações dos instrumentos básicos de ensino que possibilitaram aliar à saúde mental do educador o seu conhecimento técnico e maturidade profissional como ingredientes centrais para a criação de uma corrente pedagógica libertadora e potencializadora do ser humano. Isso se deu via Educação Nutricional da pessoa idosa, que levou a novas descobertas, bem como motivou os sujeitos para o enfrentamento de velhos paradigmas.

No que tange à dinâmica dos encontros com o grupo investigado as aulas foram ministradas no Centro de Ciências Humanas e Letras (CCHL), da Universidade Federal do Piauí (UFPI), às sextasfeiras, das $8 \mathrm{~h}$ às $10 \mathrm{~h}$, durante 31 encontros, de $2 \mathrm{~h}$, totalizando 62 horas, distribuídos em 15 e 16 encontros, no primeiro e no segundo semestre de 2005.

As atividades programáticas eram desenvolvidas utilizando-se as seguintes técnicas de ensino: pontos de reflexão e debate; comunicação oral; relato de experiências; trabalhos em grupo; dinâmicas de grupo; atividades práticas; leituras de pequenos textos, reportagens de revistas e jornais, além de técnicas de relaxamento utilizando a música.

As técnicas de ensino foram articuladas aos temas abordados e aos objetivos de cada aula, o que permitiu a elaboração de um relatório ao final de cada encontro, a gravação em audiotape e o registro imagético de algumas atividades por esta pesquisadora.

Quanto aos recursos audiovisuais que complementaram os conteúdos abordados, 
destacaram-se os seguintes: materiais educativos (cartilhas, apostila, folders); textos extraídos de revistas e jornais; cartazes; pincéis; cartolina; papel color set; alimentos; utensílios; embalagens de produtos alimentícios; pirâmide dos alimentos; CDs com as canções: "Carinhoso", "Delicado", "Luar do Sertão", "Aquarela do Brasil", "O Barquinho", dentre outras (Pedrinho Mattar - A arte do piano), aparelho de CD, gravador, fita cassete.

A amostra do estudo constituiu-se de 19 de sujeitos, com idade entre 61 a 79 anos, dos quais 2 eram do sexo masculino e 17 do sexo feminino. A identidade dos sujeitos obedeceu à seguin-te denominação: Lírio e Cravo para os homens; Angélica, Begônia, Burganville, Dália, Flor de Lis, Gérbera, Girassol, Helicônea, Hortência, Jasmim, Madressilva, Margarida, Orquídea, Violeta, Tulipa, Papoula e Petúnia para as mulheres.

Os dados foram colhidos a partir das aulas ministradas ao grupo; da observação participante, que aconteceu durante os encontros semanais, com os alunos da disciplina, permitindo as anotações no diário de campo das discussões suscitadas no decorrer do processo. Este procedimento foi inspirado em Minayo ${ }^{11}$, quando ela diz que a observação participante capta variadas situações ou fenômenos que não são obtidos por meio de perguntas, uma vez que, observados diretamente na realidade, os atores sociais, transmitem o que há de mais imponderável e evasivo na vida real.

Quanto à entrevista semi-estruturada, buscou-se o conceito de Trivinos ${ }^{14}$, que traz questionamentos básicos, apoiados em teorias e hipóteses, que interessam à pesquisa. Esta continha questões abertas segundo o roteiro (script): O que o (a) motivou a escolher a disciplina Nutrição, Saúde e Envelhecimento? O que você aprendeu após ter cursado a disciplina? Você acha que a disciplina Nutrição, Saúde e Envelhecimento contribuiu para melhorar sua qualidade de vida? O que é qualidade de vida? Sua qualidade de vida poderia melhorar? O que você entende por alimentação saudável?
Na análise das informações, procedeu-se a transcrição do conteúdo das entrevistas pelos parâmetros: 1) a organização do material (Préanálise); 2) a descrição analítica, o corpus das mensagens foi analisado com profundidade à luz das hipóteses e referências bibliográficas do campo da Educação Nutricional, Promoção da Saúde, Gerontologia Social e da Socioantropologia da Alimentação; 3) a Interpretação inferencial que se constituiu no fechamento das reflexões e conexões entre temáticas gerais e específicas, para posteriormente eleger as categorias de análise $\mathrm{e}^{9,11,15}$. Foram descartados aqueles discursos que apresentavam saturação das mensagens.

Posteriormente, estabeleceram-se correlações entre os dados das entrevistas, o relatório das aulas e as anotações do diário de campo, que possibilitou a organização das temáticas mais relevantes com suas categorias de análise: motivações dos idosos para ingressar no PTIA e para cursar a oficina, foco desta pesquisa, e os significados atribuídos à contribuição desta para a qualidade de vida em saúde, que serão discutidos no seguimento.

Quanto à organização dos protocolos éticos, o trabalho obedeceu aos princípios éticos dispostos na Resolução n 196/96, do Conselho Nacional de Saúde, especificamente no seu Artigo $\mathrm{IV}$, que aborda o respeito à autonomia do participante da pesquisa, garantindo-lhe, entre outros direitos, o seu consentimento livre e esclarecido, o sigilo das informações e a privacidade, bem como aos princípios básicos da Declaração Helsinki aprovada pela Associação Médica Mundial em 2000, concernente à pesquisa biomédica envolvendo seres humanos. O Projeto de Pesquisa foi submetido e aprovado pelo Comitê de Ética em Pesquisa (parecer $n^{\circ}$ 075/05; certificado de apresentação para apreciação ética de $n^{\circ}$ 0075.0.045.000-05/SISNEP), da Pró-Reitoria de Pesquisa e Pós-Graduação, da Universidade Federal do Piauí.

\section{RESULTADOSE DISCUSS ÃO}

No que tange às motivações apresentadas pelos idosos, quanto à sua participação na oficina 
oferecida pelo PTIA, os entrevistados se posicionaram segundo três abordagens: na primeira, eles descortinaram o processo de gerontologia educacional, via Universidades da Terceira Idade; na segunda, emergiram novas perspectivas para uma velhice ativa, participativa e segura em articulação com os aspectos biopsicossociais do ser humano; e na terceira, refletiram sobre questões do âmbito das políticas públicas de saúde e nutrição.

Optou-se por uma discussão consensual acerca destas motivações a partir da agregação desses discursos, categorizando-os nas seguintes temáticas: ensino-aprendizagem, integração social e promoção da saúde (cuidado com a saúde integral).

Maslow ${ }^{16}$ conceitua motivação como um conjunto de forças internas que mobilizam o indivíduo para atingir um dado objetivo, como resposta a um estado de necessidade, carência ou desequilíbrio.

A palavra motivação vem do latim movere, que significa mover. A motivação é, então, aquilo que é susceptível de mover o indivíduo, de leválo a agir para atingir algo, o objetivo, e de the produzir um comportamento orientado. No Dicionário Houaiss da Língua Portuguesa, motivação significa "conjunto de fatores psicológicos (conscientes ou inconscientes) de ordem fisiológica, intelectual ou afetiva, os quais agem entre si e determinam a conduta de um indivíduo".

As motivações sociais (secundárias, culturais) são aquelas que dependem essencialmente de aprendizagens, isto é, foram adquiridas no processo de socialização, dentre as quais, podese destacar a necessidade de convivência (afiliação), de reconhecimento, de êxito social, de segurança etc.

Observa-se, assim, que a motivação é algo complexo e que variáveis intrínsecas e extrínsecas influenciam o processo em determinado momento. As influências motivacionais de hoje podem ser diferentes das de amanhã, e metas em curto prazo podem preceder as de longo prazo. 0 problema é que, tornar-se ou permanecer saudável, ou aprender o que alguém precisa para um cuidado apropriado em saúde, envolve ações promocionais de cunho preventivo ${ }^{17}$.

A aprendizagem, neste contexto, representa o conjunto de processos a partir dos quais fazemos nossos uma série de conhecimentos, conceitos, habilidades etc. A aprendizagem impli$\mathrm{ca}$, em geral, mudança de comportamento por meio de experiências práticas. Só se considera que houve aprendizagem se as mudanças provocadas pela mesma forem relativamente permanentes.

Em sendo assim, compreende-se o processo ensino-aprendizagem a partir das concepções de educação em saúde, ancoradas na proposta educativa de Paulo Freire e nos Organismos Internacionais da Promoção da Saúde, os quais orientam a atividade pedagógica com o indivíduo e a coletividade no processo de participação popular, fomentando formas coletivas de aprendizado e investigação, de modo a promover o crescimento da capacidade de análise crítica sobre a realidade e o aperfeiçoamento das estratégias de luta e enfrentamento ${ }^{5,12}$.

Estas evidências podem ser apreciadas nos diferentes construtos sobre aprendizagem, que os idosos entrevistados destacaram como motivos do ingresso no PTIA e de cursar a oficina Nutrição, Saúde e Envelhecimento.

É que eu acho que vai servir tanto pra mim, como pra minha família mesmo, pra alguém pra eu orientar, eu acho que é uma coisa muito útil à pessoa saber o que deve comer; o que deve se alimentar, durante a vida mesmo, ainda mais na idade que nós estamos. Acho que é aí que devemos saber, apesar de que, desde pequena que eu acho que a pessoa deve saber como é a sua alimentação. Então, eu achei que pra mim fazer essa eu ia ter mais conhecimento do que eu já tenho (Begônia).

Além disso, espelhou-se em aportes da Gerontologia Educacional, presentes na Política 
Nacional do Idoso, para fundamentar, de maneira pertinente, a educação do idoso, no contexto da educação permanente e para contribuir no entendimento da educação como processo de mudança de atitudes sociais em relação ao cidadão idoso, contemplando a noção de que este pode ser um agente ativo e capaz.

Dessa forma, a perspectiva humanista do processo educativo tem como compromisso a valorização do crescimento pessoal, sublinhando a criatividade, a experiência subjetiva e a responsabilidade social do indivíduo neste processo.

O motivo foi conhecer a matéria sobre todos os seus aspectos acerca do Envelhecimento. De alegria de aprender muitas coisas. E conhecer novos amigos e professores e aprofundar mais sobre a Terceira ldade (Burganville).

A depoente evidencia a busca pelo conhecimento no sentido da participação, da socialização, da qualificação pessoal, do interesse pelas querelas do envelhecimento, seja no nível mais amplo ou mesmo no que tange à alimentação e à nutrição na velhice. Reforçando os objetivos propostos pelo PTIA, que estão centrados em aprofundar o debate sobre o envelhecimento populacional a partir da gerontologia educacional.

Nesse aspecto, acredita-se que os programas das universidades abertas e demais unidades de ensino possam, na prática, se constituir em espaços para a aquisição de conhecimentos, melhoria da auto-estima e ampliação da rede de sociabilidade da pessoa idosa.

Vista dessa forma, a gerontologia educacional pode ser realizada em vários formatos como educação não-formal, educação formal, atividades visando ao lazer e à sociabilidade, à reciclagem profissional, às mudanças de atitudes e ao apoio psicossocial, dentre outras.

No Brasil, esse campo alcança grande expressividade na modalidade de universidades da terceira idade, geralmente como projetos de extensão universitária. Nessa direção, reitera-se o posicionamento de Cachione $^{18}$, que ressalta os inúmeros ganhos advindos dessa proposta: a construção de espaços intergeracionais entre idosos e jovens; o ensino dialógico, uma vez que valoriza e aproveita as experiências, as capacidades cognitivas e as competências socioemocionais incorporadas pelos longevos em sua trajetória de vida; o fomento de novas demandas para investigações no âmbito do envelhecimento e da velhice.

Percebe-se assim que a integração social, nesse espaço, pode ser considerada como a capacidade de participação do idoso nas atividades sociais, econômicas e culturais da sociedade. A falta de integração social, segundo ArancetaBartrina ${ }^{19}$, pode afetar diretamente as escolhas, na participação e na realização das atividades de vida diária (AVD) (como o consumo alimentar, o preparo dos alimentos, a higiene pessoal, dentre outras) das pessoas idosas.

Em sendo assim, a integração social dos idosos em programas, grupos de convivência ou em outros projetos que tenham como princípio basilar a reinserção da pessoa idosa na família e na comunidade, pode ser alternativa válida frente à questão do envelhecimento contemporâneo. Neste estudo, os relatos de Petúnia e Orquídea realçam o conceito de integração social, com ênfase na participação de atividades sociais e na realização de atividades de vida diária:

Eu vim pro PTIA, porque eu me aposentei, aí eu fiquei sem atividade, aí eu acho muito ruim ficar parada, sem trabalhar; fui acostumada a trabalhar na comunidade, ter sempre aquele contato com gente; aí ficar longe de gente eu ia ficar doente. Então eu assisti uma entrevista e um convite na TV sobre esse programa NUPEUTI. Aí fui e perguntei pra meu filho que estuda aqui na universidade sobre que projeto é esse pras pessoas de 60 anos, pra fazer um curso extensivo; ai ele foi e me explicou que era pro idoso ter qualidade de vida. Aí eu vim aqui com ele, fiz a minha inscrição (Petúnia). 
A solidão familiar e social marginaliza o idoso levando-o à falta de esperança e à preocupação consigo. Há tendência ao desestímulo para as ações pessoais e sociais, configurando o enveIhecimento em uma rede de conflitos socioeconômicos, culturais e psicológicos.

Alguns trabalhos têm demonstrado que a má nutrição do idoso pode também ser decorrente de sua progressiva incapacidade de realizar sozinho as atividades cotidianas. As questões concernentes à capacidade funcional e à autonomia da pessoa idosa podem ser mais importantes que a própria questão da morbidade, pois se relacionam diretamente com a qualidade de vida.

Este pensamento é também compartilhado por Ramos, quando ele infere que o que está em jogo na velhice é a autonomia, ou seja, a capacidade de determinar e executar seus próprios desígnios. Acrescenta, ainda, que qualquer pessoa que chegue aos 80 anos capaz de gerir sua própria vida e determinar quando, onde e como se darão suas atividades de lazer, convívio social e trabalho (produção em algum nível), certamente, será considerada uma pessoa saudável${ }^{20}$.

Porque é um assunto que eu gosto; tenho necessidade por causa da minha idade e necessidade pra viver bem [...] por isso, nós perguntamos muito, porque nós temos pressa, a gente tem muita pressa quando está nessa idade, de saber, de entender as coisas, no meu caso de achar que o nosso tempo está correndo muito rápido e que nós temos pouco tempo, é por isso que eu procurei fazer também a disciplina de Psicologia pra complementar a sua aula (Orquídea).

A expressão de Orquídea explicita que sentido ela apreende de sua participação no PTIA, ou seja, a sua motivação para cursar as oficinas de Nutrição e de Psicologia tem um significado peculiar que perpassa sua maneira de olhar a velhice antes e após o seu ingresso no programa, denotando, assim, a sua vontade e seu prazer em viver, de se sentir sujeito desse processo.
Em uma leitura mais abrangente, significa dizer para a sociedade atual que o velho precisa ser visto, ouvido, respeitado e incluso como cidadão e como interlocutor transgeracional de sapiência. Ser velho significa ter vivências, acúmulo de conhecimentos, conquistas, projetos pessoais, o que remete a pensar a velhice como um fenômeno natural e cultural. Nesse sentido, permite, também, a desconstrução e a crítica ao atual conceito de velhice como uma variável homogênea e fixa, se analisada apenas do ponto de vista demográfico.

Outra abordagem, presente nesta pesquisa, converge para o horizonte das políticas de saúde e nutrição. Nessa perspectiva, os sujeitos investigados destacaram o cuidado com a saúde integral como a principal motivação para a sua inserção no programa e na disciplina, haja vista que esta perspectiva da promoção da saúde se apresenta e é apontada como uma das diretrizes da Política Nacional de Alimentação e Nutrição.

Nesse campo, os depoimentos que dão ênfase aos cuidados com a alimentação e nutrição modulam-se em diferentes situações, dentre as quais:

O interesse de saber mais sobre a alimentação da pessoa idosa e fora da idade também, porque tenho netos e me interessou saber mais ou menos a alimentação que leva a gente a ficar mais saudável, mais forte, viver melhor, com mais disposição, aprender mais [...] (Madressilva).

A alimentação da gente traz muitos recursos pra gente, principalmente pra nós, que já estamos na $3^{a}$ idade. $E$, às vezes, tudo ofende; não coma isso; não faça aquilo; então, eu achei que a gente pegando uma disciplina de Nutrição, ela trabalhava com a gente e a gente podia ter uma qualidade de vida melhor. Até por isso fui à Nutricionista: Ela passou umas dietas, viu? Que eu até perdi peso, eu me senti bem [...] (Dália). 
Em termos mais gerais, o cuidado faz parte da essência de todo ser humano. É aquilo que se opõe ao descuido. Cuidar, mais que um ato, é uma atitude. Representa uma atitude de ocupação, preocupação, de responsabilização e de envolvimento afetivo com o outro ${ }^{21}$. Aqui se destaca a responsabilidade social do Nutricionista frente ao cuidado com a saúde, em interconexão às práticas preventivas de saúde e nutrição, da população em geral, como reza a política nacional de saúde, inclusive ressaltando as habilidades e competências de cada profissional.

Nesse sentido, os achados desta investigação encontram fundamentos em outros estudos populacionais, realizados pelo Centro de Estudos sobre Envelhecimento (CEI/RS) e por Ramos, os quais têm demonstrado que não menos que $85 \%$ dos idosos apresentam, pelo menos, uma doença crônica, e cerca de $10 \%$ apresentam, pelo menos, cinco dessas enfermidades. A presença de uma ou mais enfermidade crônica, no entanto, não significa que o idoso não possa conservar sua autonomia e realizar suas atividades de maneira independente 20,22 .

Na compreensão do adoecer com cronicidade é importante também aquilatar perdas e ganhos do envelhecimento. Alteram-se os papéis sociais, diminuem o ritmo e a capacidade para o trabalho, surgem rugas e mudanças corporais estéticas, mas emergem também outros atributos relacionados à experiência e sabedoria. Garcia et al. ${ }^{23}$, em seu estudo sobre "Idosos em Cena: falas do adoecer", concluem que os processos mórbidos múltiplos e suas complicações podem ser minorados por meio do diagnóstico precoce ou de medidas de cunho preventivo. Entretanto, o diálogo é destacado como um elemento-chave para cuidar do sofrimento, na perspectiva de um envelhecer mais sadio.

Este argumento, também é alvo das preocupações da Política Nacional de Saúde do Idoso ${ }^{3}$, ao declarar que o principal problema que pode afetar o idoso, como conseqüência da evolução de suas enfermidades e de seu estilo de vida, é a perda de sua capacidade funcional, isto é, a perda das habilidades físicas e mentais necessárias para a realização de suas atividades básicas e instrumentais da vida diária.

Dessa maneira, as proposições de fóruns e agências internacionais de saúde assumem um conceito mais amplo de saúde, a exemplo da OMS, que, em sua Carta Magna, de 7 de abril de 1948, propõe: Saúde é um estado de completo bem-estar físico, mental e social e não apenas a ausência de afecção ou doenças ${ }^{24}$.

Posteriormente, a VIII Conferência Nacional de Saúde realizada em Brasília, no ano de 1986, conceituou a Saúde como a resultante das condições de alimentação, habitação, renda, ambiente, trabalho, emprego, lazer, liberdade, acesso à posse de terra e acesso aos serviços de saúde. É assim, antes de tudo, o resultado das formas de organização social ${ }^{25}$.

Ao buscar subsídios na Carta de Ottawa, entende-se que a promoção da saúde consiste no processo de capacitação da comunidade para atuar na melhoria da sua qualidade de vida e saúde, inclusive com uma maior participação no controle deste processo. Para tanto, os cinco principais campos de ações definidos nesta são: a elaboração e a implantação de políticas públicas saudáveis; a criação de ambientes favoráveis à saúde; o reforço da ação comunitária; o desenvolvimento de habilidades pessoais e a reorientação do sistema de saúde ${ }^{5}$.

Nesse sentido, reitera-se o posicionamento de Buss, segundo o qual a promoção da saúde caracteriza-se pela constatação de que a saúde é produto de um amplo espectro de fatores relacionados à qualidade de vida, incluindo um padrão adequado de alimentação e nutrição, de habitação e saneamento; boas condições de trabalho e renda, oportunidades de educação ao longo de toda a vida dos indivíduos e das comunidades (empowerment) $)^{26}$.

Assim, os relatos dos idosos sobre a importância dos programas da terceira idade, mediada na oficina Nutrição, Saúde e Envelhecimento, confluíram em questões-chave como o 
desenvolvimento biopsicossocial do ser humano, via aprendizagem, a saúde, a qualidade de vida e a integração social, sinalizando para o processo de educação contínuo e permanente durante todo o ciclo vital, como uma estratégia para a construção da velhice sadia.

A percepção dos sujeitos sobre a contribuição do processo ensino-aprendizagem, a partir da disciplina, se fundamenta na consciência que passaram a ter a respeito dela, seja como resultado das próprias vivências, seja pelos conhecimentos que adquiriram durante a experiência.

As vivências anteriores à disciplina mostraram-se marcantes para que as mudanças positivas fossem evidenciadas em duas direções, a primeira, versa sobre concepções da própria velhice, o seu desenvolvimento pessoal, a auto-estima. A segunda, delata o autocuidado, as alterações nas práticas alimentares e no estilo de vida (alimentação saudável, atividade física, atividade mental e equilíbrio emocional), que somadas ao suporte familiar e à independência econômica, converge para o conceito de capacidade funcional, destacando-o como um novo paradigma de saúde, particularmente relevante para o cidadão idoso ${ }^{20}$.

Ah! Trouxe muita coisa; primeiro essa disciplina me trouxe muita paz, muita paz, que é o que eu mais preciso, da minha saúde com muita paz. Então, essa disciplina eu gostei, estou gostando, e, se tivesse uma outra formatura eu iria me formar de novo com ela. Só que eu não posso me formar outra vez. Já estou formada, mas me trouxe muita tranqüilidade, muita felicidade, eu sinto saúde, eu fico com saúde quando eu estou nessa disciplina e outras e outras mais. Eu me sinto muito feliz e só me traz saúde (Girassol).

O depoimento de Girassol aviva a categoria auto-estima como uma modalidade de influências e inter-relações que convergem para a formação do indivíduo na sua totalidade, incluindo suas idéias, valores e atitudes frente aos desafios cotidianos do processo de envelhecer.

\begin{abstract}
A saúde, a alimentação. Porque, às vezes, a gente pensa que uma coisa é a gente tem que comer aquilo porque alimenta e tudo [...] e às vezes, é uma coisa que nem serve pra mim que tenho pressão alta [...] Muitas coisas eu estou mudando, é devagarzinho, porque a gente não pode ser de uma vez só, não é? Mas, estou mudando bastante a minha alimentação, me sinto muito melhor; minha pressão, agorinha mesmo, eu tirei a pressão e deu 12 por 9. Que já tem chegado a 22 [...] (Flor de Lis).
\end{abstract}

As falas das depoentes revelam suas concepções sobre a saúde na velhice, inclusive explicitando algumas mudanças no seu estilo de vida, o que possibilitou um melhor controle dos agravos à saúde.

Eu acho que melhorou bastante; agora, eu já como algumas coisas que eu não comia, agora eu já estou comendo com a ajuda das orientações e da médica também, porque ela está me acompanhando, ela me orienta e eu já como alguma coisa que eu não comia, estou me sentindo mais leve, minha barriga era grande, o estômago era alto, hoje, eu já pego aqui e nem acho mais, faço caminhada, e é isso, eu estou superbem [...] (Hortência).

Os sujeitos passaram a ter consciência da importância da educação nutricional, tanto para si, como para o longevo em geral, vendo-a como a possibilidade de viver uma velhice mais sadia e com maior qualidade, por capacitá-lo com informações importantes para suas vidas e mudanças de hábitos.

Contribuiu sim. É que ela deu uma idéia pra eu poder mudar os tipos de alimentos, eu troquei uns alimentos por outros, porque eles trazem mais saúde e benefício pra vida da gente, no dia-a-dia, como soube aprender a diminuir os ingredientes, como a gordura, eu usava outro tipo de óleo, hoje, eu já estou usando o 
de soja; estou usando a carne de soja, o grão, isso foi à coisa que me fez mudar o comportamento, como a gente vê que dá uma qualidade de vida melhor pra gente (Gérbera).

De certa forma pode-se inferir que houve a adoção de novas práticas alimentares pelo grupo investigado, que perpassam aspectos que incluem o espaço culinário, o espaço dos hábitos de consumo e temporalidade alimentar, ou seja, a organização das refeições de acordo com a idade, a atividade física e a condição de saúde.

A ênfase na socialização do conhecimento se destaca nos depoimentos como um importante balizador frente às práticas educativas de aconseIhamento dietético individual ou coletivo, assim como reitera esta abordagem pedagógica no campo da educação nutricional no envelhecimento. Demonstra-se que os aportes da disciplina podem se constituir em elementos para a desconstrução da visão universalista do próprio processo de envelhecimento humano, que o associa à fase da vida caracterizada pelo declínio. Visão esta, ainda muito presente no País.

Apesar da entrada tardia no campo de estudos sobre a saúde de pessoas idosas, a Educação Nutricional tem dado algumas contribuições fundamentais para inovar a abordagem das questões relativas ao envelhecimento contemporâneo. Este processo vem ocorrendo a partir da década de 80, com a ampliação do conceito de promoção da saúde pelos organismos internacionais responsáveis pela saúde pública, bem como pelas universidades brasileiras responsáveis pela educação gerontológica.

A abordagem pedagógica da educação nutricional se apóia no pensamento da educação crítica, a qual significa, para Paulo Freire, abertura aos outros, à disponibilidade curiosa à vida e aos seus desafios ${ }^{27}$.

Boog $^{28}$ concorda com Freire ${ }^{27}$, quando destaca que educar é um processo de mudança que ocorre, no mínimo, entre duas pessoas: educando e educador. Ser educador significa mudar conhecimentos, atitudes e ações em todas as situações que se fizerem necessárias.

Há concordância com as teses ora referidas, no sentido de que o cotidiano da sala de aula, indiscutivelmente, é um agente que converge para promoção da educação alimentar e nutricional, dos sujeitos inseridos no processo de gerontologia educacional, das universidades da terceira idade, como reza a Política Nacional do Idoso $(\mathrm{PNI})^{29}$.

É com esta abordagem que se vê a Educação em Saúde, em especial a Educação Nutricional, na medida em que o profissional de saúde, como educador que é, busca nos aportes das ciências humanas e sociais alternativas para adotar um papel de facilitador do processo de ensinoaprendizagem, em que os sujeitos assumem a educação em saúde como conceito de promoção da saúde.

O debate sobre a promoção de práticas alimentares adequadas à população, em todo o ciclo de vida, tem alcançado um espaço privilegiado na PNAN ${ }^{6}$, apesar das controvérsias quanto à sua implantação. As experiências no campo da gerontologia educacional são alguns dos exemplos positivos que ilustram esses avanços em relação aos cuidados com a pessoa idosa.

Educar o idoso para conhecer e acreditar em suas reais capacidades, desenvolver seus talentos, ensiná-lo a colocar o conhecimento a serviço de sua construção como sujeito, criar oportunidades para que aprenda a enfrentar obstáculos e preconceitos sociais, são ações que significam contribuir para promover a sua qualidade de vida e para o aprimoramento de sua cidadania ${ }^{18}$.

Vista dessa forma, a educação nutricional no envelhecimento apresenta-se como uma atitude inovadora aos novos desafios e às demandas alimentares e nutricionais geradas pela emergência de um novo segmento etário e de uma nova fase do curso de vida: a velhice.

\section{O N CLUS Ã O}

O trabalho de campo apontou evidências quanto à importância da educação nutricional 
balizada nos fundamentos da educação popular, na medida em que o diálogo, a crítica e o aprofundamento das dimensões sócio-políticas da alimentação e do alimentar-se da pessoa idosa foram determinantes no desencadeamento de querelas sociais e políticas presentes na discussão do enveIhecimento contemporâneo.

Frente às constatações desta pesquisa, considera-se fundamental discutir as abordagens teórico-metodológicas utilizadas nas práticas educativas em alimentação e nutrição, o que não significaria um retorno à perspectiva instrumental da educação alimentar e nutricional, mas sim uma tentativa de restabelecer novas relações entre o técnico e o político, pois eles se exigem entre si, e o momento demanda uma perspectiva educacional que coadune as duas dimensões, sobretudo no âmbito da gerontologia educacional.

Nesse contexto, as práticas pedagógicas da nutrição carecem de abordagens em que haja uma interlocução interdisciplinar entre as ciências da saúde e as ciências sociais, políticas e econômicas em duas direções, de um lado, para que essa supremacia do biológico sobre o sócio-cultural encontre no conceito de espaço social alimentar condições concretas para discutir as dimensões sócio-políticas da alimentação e do ato alimentar. Por outro lado, para que a manutenção da capacidade funcional da pessoa idosa, que, em sua essência, se constitui em uma atividade multiprofissional, possa subsidiar esse novo paradigma de saúde, que surge como resposta à transição epidemiológica e demográfica nas sociedades modernas.

Depreende-se, a partir da investigação, que as metodologias dialéticas do processo ensinoaprendizagem foram decisivas quanto às descobertas dessas dimensões, para além das orientações tecnológicas e informacionais do consumo alimentar, apenas no sentido de aportar quantiqualitativamente nutrientes essenciais às necessidades biológicas da pessoa idosa.

A abordagem qualitativa e o diálogo com autores que ancoraram as reflexões teóricas deste estudo descortinaram outros condicionantes da promoção da saúde humana, como as perspectivas sociais, políticas, ecológicas e culturais, que possi-bilitarão apoio teóricometodológico às ações educativas e melhor direcionamento ao processo de mudanças das práticas alimentares e do estilo de vida dos idosos.

Nesse contexto, foi possível contemplar como os idosos estão vivenciando os seus processos de envelhecimento e quais mudanças, no campo da promoção da saúde, o Programa Terceira Idade em Ação/UFPI, tem propiciado quanto ao seu bem-estar físico, mental e social.

\section{AGRADECIMENTOS}

À Coordenação do Programa Terceira Idade em Ação, da Universidade Federal do Piauí, pelo apoio na realização da pesquisa de campo, e a Francisco de Assis Silva Alencar, pelo auxílio na construção do abstract e na revisão minuciosa deste trabalho.

\section{COLABORADORES}

M.S.S. ALENCAR participou da elaboração e da redação do artigo, incluindo o planejamento, as reflexões sobre o tema e todas as revisões necessárias para a concretização deste. F.O. BARROS JÚNIOR participou da revisão do conteúdo do artigo. C.M.R.G. CARVALHO participou da elaboração e da revisão crítica do conteúdo do artigo.

\section{REFERÊ N CIAS}

1. Instituto Brasileiro de Geografia e Estatística. Síntese de indicadores sociais: 2003//BGE. Departamento de População e Indicadores sociais. Rio de Janeiro: IBGE; 2003.

2. Camarano AA, Ghaouri SK. Idosos brasileiros: que dependência é essa? In: Camarano AA, Ghaouri SK, organizadores. Muito além dos 60: os novos idosos brasileiros. Rio de Janeiro: IPEA; 1999. p.281-304.

3. Brasil. Portaria do Gabinete do Ministro de Estado da Saúde de n 1395, de 9 de dezembro de 1999, que aprova a política nacional de saúde do idoso e dá outras providências. Brasília: Diário Oficial 
[da] República Federativa do Brasil, n²37-E, p.22-24, 13 dez, seção 1; 1999.

4. Cervato AM, Derntl AM, Latorre MRDO, Marucci MFN. Educação nutricional para adultos e idosos: uma experiência positiva em Universidade Aberta para a Terceira Idade. Rev Nutr. 2005; 18(1):41-52.

5. Organização Mundial da Saúde. Carta de Ottawa, aprovada na I Conferência Internacional sobre Promoção da Saúde; 1986. [acesso 2006 mar. 28]. Disponível em: <http://www.saude.gov.br/ programas/promocaoalma.htm>.

6. Política Nacional de Alimentação e Nutrição. Secretaria de Atenção à Saúde. Departamento de Atenção Básica. 2a.ed. rev. Brasília: Ministério da Saúde; 2003.

7. Valente FLS. Direito humano à alimentação: desafios e conquistas. São Paulo: Cortez; 2002.

8. Aranceta-Bartrina J. Educación nutricional. In: Serra Majem L, Aranceta-Bartrina J, Mataix VJ. Nutrición y salud publica: métodos, bases científicas y aplicaciones. Barcelona: Masson; 1995 p.66-72.

9. Turato ER. Tratado da metodologia da pesquisa clínico-qualitativa: construção teórico-epistemológica, discussão comparada e aplicação nas áreas da saúde e humanas. 2a. ed. Petrópolis: Vozes; 2003.

10. Gil AC. Métodos e técnicas de pesquisa social. 5a. ed. São Paulo: Atlas; 1999.

11. Minayo MCS. Pesquisa social: teoria método e criatividade. 21a. ed. Petrópolis: Vozes; 2004.

12. Freire P. Pedagogia do oprimido. Rio de Janeiro: Paz e Terra; 2005.

13. Valente FLS. Em busca de uma educação nutricional crítica. In: Valente FLS, organizador. Fome e desnutrição: determinantes sociais. São Paulo: Cortez; 1989 p.66-94.

14. Trivinos ANS. Introdução à pesquisa em ciências sociais: a pesquisa qualitativa em educação. São Paulo: Atlas; 1994.

15. Bardin L. Análise do conteúdo. Lisboa: Edições 70; 1997.

16. Maslow AH. Psicologia humanista e a hierarquia das necessidades. In: Cloninger SC. Teorias da personalidade. São Paulo: Martins Fontes; 2003. p.484-514.
17. Rogers CR. Teoria centrada na pessoa. In: Cloninger SC. Teorias da personalidade. São Paulo: Martins Fontes; 2003. p.456-483.

18. Cachione M. Quem educa os idosos? um estudo sobre professores de Universidades da Terceira Idade. Campinas: Alínea; 2003.

19. Aranceta-Bartrina J. Pautas dietéticas nutricionales para la vejez. Nutr Clín. 1988; 8(6):34-40.

20. Ramos LR. Fatores determinantes do envelhecimento saudável em idosos residentes em centro urbano: projeto epidoso, São Paulo. Cad Saúde Pública. 2003; 19(3):783-89.

21. Boff L. Saber cuidar: ética do humano: compaixão pela terra. Petrópolis: Vozes; 1999.

22. Conselho Estadual do Idoso, Rio Grande do Sul. Considerações finais. In: Os idosos do Rio Grande do Sul: estudo multidimensional de suas condições de vida: Conselho Estadual do Idoso, Relatório de pesquisa. Porto Alegre: CEI-RS; 1997. p.71.

23. Garcia MAA, Odoni APC, Souza CS, Frigério RM, Merlin SS. Idosos em cena: falas do adoecer. Interface: Comunic, Saúde, Educ. 2005; 9(18): 537-52.

24. World Health Organization. Handbook of basics documents. 5th ed. Geneva: Palais des Nations; 1952. p.3-20.

25. Brasil. VIII Conferência Nacional de Saúde. Anais da VIII Conferência Nacional de Saúde. Brasília: Ministério da Saúde; 1986.

26. Buss PM. Promoção e educação em saúde no âmbito da Escola de Governo em saúde da Escola Nacional de Saúde Pública. Cad Saúde Pública. 1999; 15(Supl 2):177-85.

27. Freire P. Pedagogia da autonomia: saberes necessários à prática educativa. São Paulo: Paz e Terra; 1999. Coleção Leitura.

28. Boog MCF. Educação nutricional: passado, presente e futuro. Rev Nutr. 1997; 10(1):5-19.

29. Brasil. Lei $n .{ }^{\circ} 8.842$, de 4 de janeiro de 1994. Dispõe sobre a Política Nacional do Idoso, cria o Conselho Nacional do Idoso e dá outras providências. Brasília: Diário Oficial da República Federativa do Brasil 1996; 5 jan. 